\title{
O prescrito e o vivido na formação dos oficiais militares estaduais: a voz dos docentes
}

Getúlio Neves Sena

CBMPE/FUNDAJ

Ana de Fátima Pereira de Sousa Abranches

FUNDAJ

\section{Resumo}

O artigo apresenta um estudo sobre o currículo do Curso de Formação de Oficiais de Bombeiro Militar de Pernambuco, baseado na mudança proposta na Matriz Curricular Nacional para a formação dos profissionais de segurança pública. Neste contexto, a reforma de ensino desenvolvida nas instituições militares deixa de ter um foco militarista, com ênfase na defesa nacional e abraça princípios mais humanos visando aproximar a população das instituições de segurança pública. Os dados coletados evidenciam a necessidade de serem repensados o novo perfil, a identidade e as competências do Bombeiro Militar, a inserção social e a falta de contextualização dos conteúdos.

Palavras-chave: Bombeiro Militar. Currículo. Formação de Oficiais. Currículo. Instituições Totais. 


\section{El prescrito y el vivido en la formación de los oficial militares estaduales: la voz de los docentes}

\section{Resumen}

El artigo presenta un estudio acerca del currículo del Curso de Formación de Oficiales de Bombero Militar de Pernambuco, con base en el cambio propuesto en la Matriz Curricular Nacional para la formación de profesionales de seguridad pública. En este contexto, la reforma del enseño desarrollada en las instituciones militares deja de tener un enfoque militarista, con énfasis en la defensa nacional, y abraza principios más humanos, visando aproximar la población de las instituciones de seguridad pública. Los datos colectados evidencian la necesidad de repensar el nuevo perfil, la identidad y las competencias del bombero militar, la inserción social y la falta de contextualización de los conteúdos.

Palabras clave: Formación de oficiales. Currículo. Bombero Militar. Currículo. Instituciones Totales. 


\section{The prescript and the living in the training of state military officers: the voice of teachers}

\section{Abstract}

The article presents a study about the curriculum of the Pernambuco's Military Firefighter Training Course, based on the proposed change in the National Curriculum Matrix for the training of public safety professionals. In this context, the reform of education developed in military institutions no longer has a militaristic focus with emphasis on national defense, and embraces more human principles aimed at bringing the population closer to public security institutions. The data collected evidences the need to rethink the new profile, the identity and the competences of the Military Fire Brigade, the social insertion and the lack of contextualization of the contents.

Keywords: Officials training. Curriculum. Military Firefighter. Curriculum. Total Institutions.

\section{Le prescript et la vie dans la formation des officiers militaires d'etat: la voix des enseignants}

\section{Resumé}

Cet article présente une étude sur le programme d'études du cours de formation des pompiers militaires de Pernambuco, basé sur le changement proposé dans la matrice de programme national pour la formation des professionnels de la sécurité publique. Dans ce contexte, la réforme de l'éducation développée dans les institutions militaires, n'a plus de visées militaristes, mettant l'accent sur la défense nationale et embrasse des principes plus humains visant à rapprocher la population des institutions de sécurité publique. Les données collectées témoignent de la nécessité de repenser le nouveau profil, l'identité et les compétences des pompiers militaires, l'insertion sociale et le manque de contextualisation du contenu.

Chercher: Formation des officiers. Curriculum Pompier militaire. Curriculum Total des institutions. 


\section{Introdução}

Ao longo da formação e constituição das instituições militares de Segurança Pública (Polícia Militar e Corpo de Bombeiros Militar), a doutrina militarista do Exército brasileiro apresentou influência hegemônica nos cursos. Desse modo, as funções de tais instituições, por vezes, chegavam a confundir-se, sobretudo nos tempos em que o Brasil viveu a Ditadura Militar a partir de 1964. Portanto, a história recente de nosso País demonstra que tais instituições se complementavam em suas atividades de repressão à população em defesa da Ditadura Militar brasileira.

Por outro lado, percebe-se que somente a partir das últimas décadas do século XX os Corpos de Bombeiros Militares passaram a constituir-se como instituições independentes e separadas da Polícia Militar. No entanto, os Corpos de Bombeiros ainda preservam traços de tradições fortes de suas coirmãs.

Nesse sentido, a formação dos Oficiais nas Academias militares dos diversos Estados da Federação possui uma tradição pautada nos princípios de hierarquia e disciplina com os quais os "soldados" são formados para cumprir as ordens dos superiores, sem questioná-las.

Com a promulgação da Constituição Federal de 1988, ao final da Ditadura Militar, os espaços para uma polícia autoritária e repressiva começaram a desaparecer. A sociedade preza por uma polícia defensora dos seus direitos e que esteja ao seu lado, contribuindo para uma sensação de bem-estar social. Dessa forma, alguns anos mais tarde, já na primeira década do século XXI, ocorre a criação da Secretaria Nacional de Segurança Pública, tendo por objetivo servir como um fórum nacional de Segurança Pública, estabelecendo as diretrizes e o planejamento para tal área em todo o País.

Como base para suas atividades, a Secretaria Nacional de Segurança Pública (SENASP) passa a atuar na área de formação dos profissionais da Segurança Pública e por isso define diretrizes básicas para a formação de tais profissionais, elencando um rol de conhecimentos a serem adquiridos para o desempenho das atividades laborais destes. Assim, foi instituída a Matriz Curricular Nacional (MCN) para as ações formativas dos profissionais de Segurança Pública que passa por revisões periódicas e sofre modificações e inserções de novas diretrizes como forma de aperfeiçoar a política de formação na área de Segurança Pública.

O ingresso no Corpo de Bombeiros Militar de Pernambuco (CBMPE) pode ocorrer de duas formas: ou através do Curso de Formação de Praças, elemento eminentemente executor na organização hierárquica da instituição; ou por meio do Curso de Formação de Oficiais Bombeiro Militar, doravante denominado CFO/BM, que em muitos Estados é conhecido como a Escola de Comandantes por preparar os alunos para assumirem as posições de chefia na cadeia hierárquica das corporações militares estaduais.

Ao analisar o perfil do corpo discente do CFO/BM, com base sobretudo na faixa etária 
e no grau de instrução dos que o compõe, percebe-se que tratam-se de jovens, com média de idade entre os 18 e 23 anos que, em sua grande maioria, possuem ensino superior incompleto.

Nesse sentido, os discentes ingressam no Corpo de Bombeiros Militar de Pernambuco (CBMPE) ainda muito jovens, passam por um processo de adaptação à nova realidade experimentada na caserna e inserem-se num contexto específico de formação profissional completamente distinto da formação acadêmica vivida nas Universidades e Faculdades do meio civil.

Outrossim, estes jovens, ao final do período de estudo, devem estar preparados a enfrentar situações que perpassam os conhecimentos adquiridos em cada disciplina do curso de formação uma vez que tanto dentro do ambiente militar quanto nas ocorrências diárias em que tais jovens atuarão é possível observar um emaranhado de relações sociais que desenvolvem-se de maneira particular e que possuem características próprias. Tais relações podem ser observadas pelo viés sociológico, antropológico, histórico e econômico.

Com a busca pelo entendimento da Política de Formação dos Bombeiros Militares em Pernambuco, verifica-se que, para o estabelecimento de diretrizes gerais quanto à formação de tais profissionais, o Estado de Pernambuco está alinhado com a política da Secretaria Nacional de Segurança Pública (SENASP), órgão vinculado ao Ministério da Justiça e que visa ao desenvolvimento de uma política de formação em segurança pública com cidadania, focando principalmente a temática de promoção dos direitos humanos.

Partindo desse princípio, no ano de 2003 foi elaborado pela SENASP um documento denominado Matriz Curricular Nacional com o objetivo de estabelecer padrões mínimos para a formação dos agentes de segurança pública. Já em 2005 tal documento foi revisado, tendo sido incorporadas a ele as Diretrizes Pedagógicas para as atividades formativas dos profissionais da área de segurança pública e a Malha Curricular Nacional para as tais atividades.

Face o exposto, inaugurou-se um período de reforma do ensino desenvolvido nas instituições militares, abandonando-se o foco militarista com ênfase na defesa nacional, e adotando-se princípios mais humanos visando aproximar a população das instituições de segurança pública.

Ao conhecer a proposta da SENASP acerca da base nacional comum para as ações formativas dos profissionais de Segurança Pública refletimos sobre a real utilização de tal proposta para além do prescrito nos documentos oficiais, uma vez que, em um ambiente formativo, o contrato didático também faz-se presente através da relação que se estabelece entre o professor, o aluno, a instituição e o conhecimento a ser transmitido (Cruz, 2013, p. 19-20).

Partindo do pressuposto de que as políticas curriculares não são reproduzidas no 
contexto escolar de maneira isenta de valores e julgamentos, há que pensar-se na possibilidade de modificações de tais políticas no momento em que estas atingem o campo de implementação, ou seja, na prática do currículo vivido.

Este artigo busca compreender o Curso de Formação de Oficiais a partir da representação dos docentes/instrutores do curso em pauta, confrontando tais visões com o currículo oficial prescrito nos documentos norteadores do curso. Entendendo que a simbiose entre o que se vive e o que se planeja para ser vivido merece uma atenção especial para o adequado entendimento das variadas faces nas quais traduzem-se as políticas curriculares.

A pesquisa foi realizada com os docentes/instrutores do curso que funcionou no período de 2008 a 2010 por tratar-se do único CFO/BM realizado no Estado de Pernambuco após o surgimento da Malha Curricular Nacional, em 2005, o que corresponde ao curso que, em tese, seguiria outras bases filosóficas para Formação de Oficiais.

\section{Percurso metodológico}

A pesquisa qualitativa foi a escolhida em virtude do movimento existente das relações que se processam em um ambiente educacional, sobretudo quando tal ambiente reveste-se de particularidades próprias e que encaixam-se na conceituação de instituições totais que apresentam peculiaridades que modificam as características pessoais dos cidadãos submetidos a tal regime.

De acordo com Goffman (2015), uma das principais características das Instituições Totais é a quebra de barreiras entre as instâncias da vida humana referentes ao trabalho, descanso e diversão. Assim, tais instâncias, numa instituição total, não são separadas e ocorrem em um mesmo lugar, com o mesmo grupo de pessoas e sob a supervisão de um pequeno grupo cuja função resume-se ao controle dos "internos".

Ainda alicerçado nos conceitos do mesmo autor (Goffman, 2015), em Instituições Totais é nítida a divisão da comunidade formadora de tal instituição em dois grupos diferentes: de um lado o grupo dos internados e do outro a pequena equipe de supervisão. Estes não estão totalmente integrados na instituição total, possuindo contatos frequentes com o mundo exterior; enquanto aqueles se submetem a contatos restritos com o ambiente fora da instituição total. Nesse sentido, vale ressaltar que cada agrupamento tende a conceber o outro através de estereótipos limitados e hostis - a equipe dirigente muitas vezes vê os internados como amargos, reservados e não merecedores de confiança; os internados por sua vez veem os dirigentes como condescendentes, arbitrários e mesquinhos (Goffman, 2015, p. 19). 
Diante de tal situação, percebe-se a primeira das grandes dificuldades do ensino militar, uma vez que grande parte dos cursos de formação é realizada em regime de internato ou semi-internato, caracterizadas nas academias militares como Instituições Totais. Portanto, a abordagem qualitativa foi a alternativa mais adequada à presente pesquisa por representar uma forma de análise em que todo o processo investigativo foi levado em consideração e onde as análises realizadas foram construídas a partir do entendimento de todo o processo que desenvolveu-se para a obtenção dos dados.

Posto isso, com base no currículo oficial prescrito para o CFO/BM da turma de Aspirantes 2010, procuramos identificar a percepção de tal currículo e a aplicação deste na prática cotidiana vivida no ambiente formativo da Academia Integrada de Defesa Social.

Nesse sentido, Apple (2002, p. 41) destaca que "enquanto não levarmos a sério a intensidade do envolvimento da educação com o mundo real das alternantes desiguais das relações de poder, estaremos vivendo em um mundo divorciado da realidade".

A análise documental da grade curricular do curso estudado e da Matriz Curricular Nacional da SENASP, juntamente com as suas atualizações e os documentos norteadores do funcionamento da instituição de ensino em pauta (regimento interno, legislações militares aplicáveis ao corpo docente do curso estudado, aos discentes e ao corpo técnico da instituição), como também as entrevistas realizadas com os docentes constituíram o corpus de análise.

Os atores da pesquisa foram os coordenadores e os docentes/instrutores do último curso CFO/BM realizado em Pernambuco, com o objetivo de entender a representação deles sobre o currículo e sobre as relações pedagógicas. Objetivando dar voz aos sujeitos envolvidos no processo de formação dos Oficiais do Corpo de Bombeiros Militar de Pernambuco (CBMPE), foram constituídos critérios para delimitar os participantes da pesquisa. Estabelecemos os dois principais grupos da equipe escolar envolvidos na formação ocorrida na Academia Integrada de Defesa Social (ACIDES), quais sejam: os docentes/instrutores e os coordenadores pedagógicos. Ressaltamos que esses últimos são os responsáveis tanto pela parte pedagógica propriamente dita, com orientações aos docentes, planejamento e execução do curso, acompanhamento e avaliação dos alunos, como também pela parte militar e disciplinar dos alunos.

No curso, boa parte das disciplinas foram ministradas por instrutores e professores que não pertenciam ao CBMPE; no entanto, um dos critérios para a escolha dos sujeitos da pesquisa foi o de serem Bombeiros em virtude de entender que tais profissionais vivem a realidade da Corporação e, por isso, são capazes de conceituar como devem ser formados os Oficiais do CBMPE e, consequentemente, poderão ressignificar o currículo prescrito.

As disciplinas do currículo prescrito do Curso de Formação de Oficiais de Bombeiro Militar (CFO/BM) foram agrupadas em componentes curriculares, sendo este outro 
critério para seleção dos entrevistados com o objetivo de contemplar os componentes curriculares do curso. Assim, foram determinados os seguintes componentes curriculares:

Formação Humana: têm como objetivo principal desenvolver o pensamento reflexivo nos alunos, indagando-os sobre os processos sociais que desenvolvem-se entre a Corporação e a sociedade como um todo. Envolvem disciplinas como Sociologia Geral, Psicologia, Direitos Humanos, Ética e cidadania, entre outras.

Ciclo Operacional: são aquelas disciplinas que buscam construir o conhecimento técnico-profissional no discente. Caracterizam-se por ser, em sua maioria, disciplinas que precisam ensinar procedimentos técnicos e padronizados em torno da profissão aliados à realidade prática que deve ser apresentada em tais disciplinas. Envolvem disciplinas como Salvamento em altura, Salvamento aquático, Salvamento terrestre, Técnicas de Combate a incêndio, Técnicas de prevenção de incêndio, entre outras.

Após a definição dos componentes curriculares, os docentes/instrutores escolhidos para a participação na pesquisa foram aqueles que estiveram mais tempo presentes na formação dos Aspirantes 2010, preferencialmente durante os três anos de formação. Nesse sentido, a amostra consistiu em dois docentes/instrutores - um para cada componente curricular - e dois coordenadores do curso, totalizando quatro entrevistas. Desse modo, ao longo do artigo os docentes são caracterizados como DOC1, DOC2, DOC3 e DOC4.

\section{Referencial teórico}

Ao tratar do tema Currículo é importante situar o leitor diante da complexidade que abarca tal conceito. Pacheco (2005, p. 29) afirma que desde 1663 a palavra já encontrava-se definida através do dicionário correspondendo a "um curso regular de estudos numa escola ou numa universidade". Nesse sentido, o mesmo autor associa o conceito de currículo a uma trajetória que os indivíduos deveriam seguir para alcançar um determinado objetivo, ou seja, as finalidades educativas de cada curso específico estariam traduzidas no currículo que, por sua vez, consistiria numa espécie de manual de instruções para obter-se o "sucesso" ao final da jornada.

No entanto, tal panorama começa a modificar-se, pois

enquanto expressão de um projecto de escolarização, o conceito de currículo tem sofrido, ao longo dos tempos, uma erosão natural que o tem transportado desde uma concepção restrita de plano de instrução até uma concepção aberta de projecto de formação, no contexto de uma dada organização (Pacheco, 2005, p. 30).

Partindo-se para discussões que focam a teorização sobre o tema para além de 
requisitos e análises meramente técnicas, Macedo et al. (2011, p. 53) identificaram que no processo de formulação dos currículos "a seleção de conteúdos e a sua inserção em campos disciplinares específicos da escola nada têm de técnico, fazendose como um processo histórico e conflituoso".

Para Pacheco (2005, p. 33) também pode-se entender o currículo como um "projecto que resulta não só do plano das intenções, mas como do plano da sua realização no seio de uma estrutura organizacional".

Face o exposto, o presente tópico tem como objetivo apresentar o referencial teórico que norteou as concepções de currículo e de políticas curriculares adotadas nesta pesquisa.

A corrente teórica adotada no estudo deste artigo parte do princípio adotado por Almeida e Silva (2014, p. 1443) de que

as políticas curriculares não podem ser interpretadas como propostas prontas e inquestionáveis que são apenas executadas pelos sujeitos que atuam no campo da prática, sem nenhuma modificação entre o texto prescrito e o currículo vivenciado no ambiente educacional.

Visto isso, partilhamos da indagação de Macedo et al. (2011, p. 12): "será por essa razão que as tantas e sucessivas reformas educacionais não fazem lá tanto sucesso?"

Partindo do pressuposto de que as políticas curriculares não são reproduzidas no contexto escolar de maneira isenta de valores e julgamentos, há que se pensar na possibilidade de modificações de tais políticas no momento em que elas atingem o campo de implementação, ou seja, na prática do currículo vivido.

Nesse sentido, os pesquisadores ingleses Stephen Ball e Richard Bowe (1992) desenvolveram uma abordagem que trata do ciclo de "vida" das políticas públicas, enfatizando as relações com as políticas educacionais. Para estes autores, o processo de formulação e implementação de políticas constitui-se numa ação dinâmica e flexível que sofre influências mútuas dos diversos atores que entrarão em contato com a política.

Assim, é criado um modelo teórico que aborda as políticas em torno de um ciclo que interconecta-se na produção de tais políticas. Dessa forma, são constituídos três campos independentes, mas que não podem ser dissociados:

O primeiro contexto é o contexto de influência onde normalmente as políticas públicas são iniciadas e os discursos políticos são construídos. É nesse contexto que grupos de interesse disputam para influenciar a definição das finalidades sociais da educação e do que significa ser educado. Atuam nesse contexto as redes sociais dentro e em torno de partidos políticos, do governo e do processo legislativo (Mainardes, 2006, p. 51). 
Inicialmente Ball e Bowe haviam incluído os docentes e dirigentes escolares como parte do grupo de influenciadores da produção das políticas, o que veio a ser modificado com o aprofundamento de seus estudos sobre as políticas educacionais. Com isso, os autores afirmaram que é no contexto da influência onde são produzidos os discursos que legitimam as propostas políticas que são apresentadas na arena de debates. Outrossim, é também por intermédio do contexto da influência que percebe-se o poder das ideias políticas internacionais na formulação das políticas nacionais, mediante mecanismos internacionais que "vendem" suas fórmulas para um contexto social diferente dos seus.

Um segundo contexto diz respeito à produção do texto político propriamente dito. Entende-se como texto político a representação da própria política.

Essas representações podem tomar várias formas: textos legais oficiais e textos políticos, comentários formais ou informais sobre os textos oficiais, pronunciamentos oficiais, vídeos etc. Tais textos não são, necessariamente, internamente coerentes e claros, e podem também ser contraditórios (Mainardes, 2006, p. 52).

Desse modo, o texto político é composto e formulado através de disputas entre os grupos envolvidos. Portanto, na sua leitura e análise devem ser levados em consideração o contexto geral em que ocorreu a sua produção.

Diante disto, percebe-se que

a maior parte das políticas são frágeis, produto de acordos, algo que pode ou não funcionar; elas são retrabalhadas, aperfeiçoadas, ensaiadas, crivadas de nuances e moduladas através de complexos processos de influência, produção e disseminação de textos e, em última análise, recriadas nos contextos da prática (Ball, 2001, p. 102).

O terceiro contexto, já citado acima, tem relação com a prática de implementação das políticas. Assim, "o contexto da prática é onde a política está sujeita à interpretação e recriação e onde a política produz efeitos e consequências que podem representar mudanças e transformações significativas na política original" (Mainardes, 2006, p. 53).

Na produção e implementação de políticas educacionais e curriculares, vários atores e instâncias - contextos - atuam no desenvolvimento de cada proposta. Desta forma, os contextos globais e locais, assim como as instâncias oficiais e não oficiais, participam de uma interconexão que dará vida a uma política específica. Nesse sentido, alguns autores (Lopes, 2005, 2008; Mainardes \& Stremel, 2010) buscam realizar a análise das implicações dessas interconexões ocorridas no âmbito das políticas educacionais e curriculares a partir do conceito de recontextualização desenvolvido por Basil Bernstein.

Para Bernstein (como citado em Lopes, 2008, p. 27) "a recontextualização constitui- 
se a partir da transferência de textos de um contexto a outro, como da academia ao contexto oficial de um Estado nacional, ou do contexto oficial ao escolar".

Para Mainardes e Stremel (2010, p. 41), a teoria do dispositivo pedagógico, organizada por Bernstein "foi elaborada como um modelo para analisar o processo pelo qual uma disciplina ou um campo específico de conhecimento é transformado ou 'pedagogizado' para constituir o conhecimento escolar, o currículo, conteúdos e relações a serem transmitidas".

Em tratando-se da teoria do discurso pedagógico, é no seu âmbito que o conceito de recontextualização será desenvolvido. Em linhas gerais, Benstein (como citado em Mainardes \& Stremel, 2010, p. 43) caracteriza o dispositivo pedagógico como dotado de regras de três tipos: distributivas, recontextualizadoras e avaliativas.

As regras recontextualizadoras são as regras constituintes do discurso pedagógico. Baseado nelas, o discurso inicial passa por uma transformação até tornar-se um novo discurso.

Bernstein (como citado em Lopes, 2005, p. 54)

interpreta que os textos, assinados ou não pela esfera oficial, são fragmentados ao circularem no corpo social da educação, alguns fragmentos são mais valorizados em detrimento de outros e são associados a outros fragmentos de textos capazes de ressignificá-los e refocalizá-los.

Portanto, "pode-se dizer que é uma transformação ideológica, uma vez que está sujeita às visões de mundo, aos interesses especializados e/ou políticos dos agentes recontextualizadores, cujos conflitos estruturam o campo da recontextualização" (Mainardes \& Stremel, 2010, p. 43).

Diante de tal situação, inúmeros sujeitos podem atuar como atores no processo de recontextualização tendo em vista que estão em contato direto com a prática da implementação dos textos oficiais.

\section{A representação dos Docentes/Instrutores sobre o CFO/BM e a relação teoria e prática: remontando fragmentos}

Na primeira pergunta, os entrevistados foram questionados sobre a importância das disciplinas ministradas por eles para a formação dos Oficiais do CBMPE, sendo que para os coordenadores a pergunta consistia em destacar a importância de um currículo tão diversificado em termos de áreas de conhecimento. Chamamos atenção aqui ao fato de que os dois docentes/instrutores entrevistados faziam parte de componentes curriculares distintos, um representando o eixo de formação humana e o outro o eixo 
técnico profissional com disciplinas da área operacional.

Em linhas gerais, os docentes/instrutores opinaram que as disciplinas ministradas nos dois componentes curriculares elencados eram importantes por desenvolver o pensamento crítico social nos alunos e, por outro lado, fazer parte da atividade-fim da corporação. Então, se as disciplinas de formação humana atuam no sentido de formar um profissional cidadão, as disciplinas operacionais têm como objetivo dotar os alunos dos conhecimentos técnicos necessários para o desempenho da atividade-fim da corporação. Por sua vez, os coordenadores disseram acreditar que toda essa gama de disciplinas era importante, sendo que o DOC4 julgou que muitas delas eram utilizadas para preencher requisitos formais junto ao MEC para o reconhecimento do curso como nível superior. Já o DOC2 explicou que as atividades a serem desenvolvidas por um Tenente da Corporação envolvem diferentes habilidades, sejam de gestão administrativa, jurídica ou operacional. Portanto, o currículo precisa dar conta de toda essa gama de conhecimentos a serem construídos pelos alunos.

Partindo desse pressuposto, é importante ressaltar que a Matriz Curricular Nacional para a formação dos Agentes de Segurança Pública (Matriz, 2014), alicerçada em pesquisas realizadas com o intuito de construir o perfil profissiográfico de um Bombeiro Militar, demonstra que as competências exigidas para tal profissão perpassam os conhecimentos desenvolvidos por diversas áreas do conhecimento científico; além de que o Bombeiro Militar precisa "ser flexível" (Matriz, 2014, p. 35), ou seja, não pode permanecer enrijecido e convicto de que existirá uma fórmula para o desempenho da labuta diária, mas tem a necessidade de utilizar e "atravessar" diversos campos do conhecimento no desempenho de suas atividades, sejam elas operacionais ou administrativas. Portanto, é verdade que o currículo do CFO/BM precisa dar conta de diversas competências a serem adquiridas pelos Bombeiros Militares; no entanto deve-se ter cautela com o crescimento da quantidade de informação repassada aos alunos, sobretudo se esta vier de forma descontextualizada, uma vez que, de acordo com Morin (2003, p. 16) "o crescimento ininterrupto dos conhecimentos constrói uma gigantesca torre de Babel, que murmura linguagens discordantes". Dessa forma, uma variada quantidade de conteúdos do curso pode tornar-se de pouca utilidade ou até mesmo inútil a tais pessoas no momento em que sua relação com a prática profissional não é percebida nem tampouco contextualizada no ambiente educacional. Por conseguinte, é preciso remontar os fragmentos dos ensinamentos adquiridos no CFO/BM para que a aprendizagem possa tornar-se significativa.

Um segundo questionamento feito abordou sobre o tempo curricular dispensado para o CFO/BM, bem como sobre as ementas das disciplinas. Nesse ponto, o DOC3 se limitou a discutir apenas as disciplinas ministradas por ele, as quais faziam parte do componente curricular de formação humana. De acordo com ele, "em termos de carga horária eu acho que é uma carga horária satisfatória. Em relação às ementas, aos conteúdos, eu faria revisões, nas duas disciplinas (História de Pernambuco e 
Institucional, e Sociologia Geral). Acho que elas estão descontextualizadas ${ }^{1}$. Acho que é necessário ter uma discussão mais atual". Ou seja, este docente reconhece a necessidade de reformar as disciplinas, contextualizando-as de acordo com a realidade atual a ser enfrentada pelos futuros profissionais. Não obstante tal afirmação, é importante deixar claro que tal docente não se refere à integração e contextualização curricular como um todo, mas pontua a necessidade de reforma das disciplinas de formação humana ministradas por ele.

Já os demais entrevistados preferiram fazer uma análise geral acerca do curso, perpassando a sua carga horária total, assim como a divisão das disciplinas por áreas de conhecimento. Tanto o DOC1, que atuou como coordenador do CFO/BM em turmas anteriores, quanto o DOC4 acreditam ser a carga horária total do CFO/BM insatisfatória em virtude da quantidade de conhecimentos que os alunos precisam adquirir, pois "os alunos ficam numa pressão muito grande, tendo aulas no período da manhã, no período da tarde e algumas vezes no período da noite; o que, pela formação educacional, não contribui 100\% para uma boa formação, né?" (DOC4)

Saliento que tais informações vão de encontro com as respostas dos ex-discentes aos questionários aplicados, uma vez que $63 \%$ dos que responderam o questionário acreditavam que o curso poderia ser reduzido, assim como somente $12,5 \%$ sentiamse totalmente preparados para a atuação profissional. Nessa perspectiva, importante observação é feita pelo DOC2 ao tratar sobre a questão do currículo do CFO/BM:

Eu acho que o grande problema da gente é que a gente nunca fez uma pesquisa pra saber qual é o objetivo que a gente quer... a gente nunca partiu desse princípio de fazer um estudo de o que é que a gente quer de um oficial pra a partir daí a gente desenvolver esse currículo; e a partir desse objetivo que a gente vai traçar é que, eu posso dizer se o meu currículo em 3 anos ele é muito longo, é muito curto; se ele pode ser reduzido;

Com base no exposto, trazemos a reflexão de Morin (2013, p. 37) quando esse autor prega a necessidade de reformar o conhecimento. Segundo ele, tal reforma "deve originar-se dos próprios professores e não do exterior". Então, os professores/ instrutores/coordenadores do CFO/BM é que, em conjunto e com debates técnicos, podem decidir o que espera-se de um Tenente do CBMPE e como deve ser a formação deste Oficial. Acreditamos que sem esse debate a Corporação permanecerá arraigada a antigas tradições que já não respondem aos anseios sociais para com os profissionais de Segurança Pública, nem tampouco poderá dar efetividade à política nacional de reforma do ensino em tal área.

Prosseguindo nas entrevistas, os Oficiais foram perguntados sobre os conhecimentos que balizaram a atuação como docentes, para os instrutores, e qual o papel do coordenador, para os coordenadores.

1 Grifo do autor. 
Ambos os instrutores falaram de uma falta de doutrina de formação no CBMPE; eles balizaram suas atuações como docentes em conhecimentos adquiridos fora do CBMPE, seja no âmbito civil, para o instrutor das disciplinas de formação humana, DOC3, seja em outras corporações militares (nos Estados do Pará, Rio Grande do Norte, Alagoas, Paraíba, entre outros), para o instrutor das disciplinas de formação profissional, DOC1. Nesse mesmo caminho encontram-se as respostas relacionadas ao papel dos coordenadores, uma vez que o DOC4 afirmou que "minha função é ser o elo direto dos sessenta e dois alunos para levar para o comando e tentar administrar da melhor forma a convivência dos três anos de curso". Por outro lado, o DOC2 destacou que um grande problema está em que

nem essa definição das funções do coordenador existem... eu estou lá pra resolver todos os problemas que estejam relacionados com os alunos oficiais do corpo de bombeiros, sejam eles problemas disciplinares, familiares, pedagógicos, administrativos, os mais diversos.

Nesse ponto, percebe-se que existe a ausência de uma política de formação para o CBMPE, uma vez que corrobora o proposto por Luiz (2008, p. 92) "uma boa Polícia, por óbvio, não pode ser refém do chefe do Executivo. Precisa, frequentemente, saber posicionar-se para assegurar o que realmente importa e não se perder com as mirabolantes ideias que traz cada novo governante". Portanto, sem uma política de formação estabelecida o CBMPE fica à mercê de vontades políticas que manipulam o ingresso e o modelo de formação dos militares estaduais da forma que melhor lhes convém, tornando o curso frágil no sentido de organização, metodologia e didática. Os coordenadores se classificaram como pessoas que estavam presentes no curso para resolver questões disciplinares, pedagógicas e outros. No entanto, chegaram a dizer que não existia uma definição da sua função.

Conforme as observações trazidas acima, pode-se ajuizar que até mesmo as atribuições dos formadores e coordenadores do curso ora estudado fazem parte de modelos próprios construídos por cada docente/coordenador com base na experiência profissional de cada um para balizar as suas atuações, não correspondendo a um modelo de formação pensado pela corporação no seu conjunto e sistematizado em uma proposta efetiva de como formar o Oficial do CBMPE. Nesse sentido, a dissociação da teoria com a prática é uma realidade que apresenta-se como um desafio a ser vencido, exigindo da Corporação uma tomada de decisão urgente para refletir acerca dessa formação.

Ainda sobre a percepção em torno do currículo, os docentes foram indagados sobre a proposta da SENASP de Segurança Pública com cidadania, através de uma formação humana para os agentes que integram esse segmento profissional.

Nesse ponto todos os entrevistados mostraram-se reticentes em como fazer acontecer tal propósito. Dois deles, DOC2 e DOC3, falaram sobre a importância e 
a exigência de implantar a Matriz Curricular Nacional no CFO/BM sob pena de não autorização do funcionamento do curso; entretanto eles próprios criticam a proposta da SENASP por não levar em consideração as diferenças regionais na implantação de uma base comum para todos os cursos de formação para agentes de Segurança Pública. "A intenção é importante, mas o trabalho foi muito pensado na realidade do Sudeste", afirmou o DOC3. "É importante que a gente lembre que a gente vive num país com dimensões continentais. Então, existem características da região Nordeste que são muito especificas da região", destacou o DOC2.

Por outro lado, os demais entrevistados demonstraram preocupação com a inserção de tais disciplinas sem modificar-se a duração do curso tendo em vista que para a implantação de disciplinas com características humanísticas que não existiam em cursos anteriores foi necessária uma readequação das que existiam, diminuindo-se a carga horária de algumas. Dessa forma, para o DOC1 "a formação humana ela é imprescindível, ela tem de haver. Porém o que não pode é uma coisa suplantar a outra".

No currículo prescrito para o CFO/BM, menos de $20 \%$ da carga horária são disponibilizadas para as disciplinas de formação humana; entretanto, a preocupação com a formação técnica é latente, sobretudo em virtude do modelo institucional hierarquizado.

Partindo desse princípio, o DOC3 também chamou atenção para a mudança de atitude necessária para a implantação de práticas humanas na formação dos militares, uma vez que não se criou uma cultura institucional que valorize esse tipo de formação. Dessa forma,

acho que o resultado que se espera, uma mudança, ele não necessariamente vai ser atingido porque trabalhar, por exemplo, direitos humanos quando a pessoa que está responsável por trabalhar essa temática ela não necessariamente entende essa necessidade, fica difícil; o modelo antigo vai continuar sendo reproduzido. (DOC3)

Essa asserção reafirma a necessidade da discussão do curso pela corporação. Desde os objetivos, a formação dos docentes que ministrarão aulas no curso, o estágio, a relação teoria e prática e a relação com a sociedade.

A situação apontada demonstra que uma vez que o docente designado para trabalhar a temática não tem domínio sobre o tema e nem muito menos afinidade, torna a política proposta para o curso letra morta na realidade educacional das escolas de formação militar. 


\section{O distanciamento da sociedade: paradoxos de uma formação para o serviço da sociedade}

Partindo para o segundo bloco de perguntas procura-se identificar nesse momento as práticas docentes desenvolvidas ao longo do CFO/BM. Dessa forma, questões sobre a atividade docente no dia a dia do CFO/BM, as estratégias para a construção do conhecimento, a percepção sobre os alunos e as competências que estes deveriam adquirir ao final da disciplina ou mesmo do curso e as práticas desenvolvidas que tiveram como escopo a implantação da MCN. Por fim, os entrevistados deveriam apresentar os principais desafios enfrentados enquanto instrutores/coordenadores do CFO/BM e quais as mudanças que eles promoveriam em uma nova atuação em tais funções.

Inicialmente, o DOC2 salientou as dificuldades iniciais para que o curso acontecesse. Como o sistema de ensino da Secretaria de Defesa Social passava por uma migração, integrando todos os Órgãos de Segurança Pública e adotando as diretrizes nacionais para a formação dos profissionais da citada Secretaria, o CBM/PE, através dos militares que trabalhavam na antiga Academia de Polícia Militar de Paudalho (APMP), que tornava-se naquele momento Academia Integrada de Defesa Social/Campus de Ensino Mata (ACIDES/CEMATA), precisava adequar-se às novas diretrizes e, para tanto, necessitava construir um novo projeto pedagógico e, num mesmo documento, um planejamento geral de execução do curso - chamado no âmbito da ACIDES de projeto de curso. Com isso, o DOC2 afirmou que todo esse planejamento necessário foi realizado num prazo de 30 dias.

Passada essa problemática inicial, os instrutores entrevistados foram bastante enfáticos ao afirmar que a base da formação dos Oficiais estava no relacionamento que iria ser construído com a equipe de instrução. Para eles, uma mudança curricular e de pensamento institucional para a formação passa pela forma como os instrutores se portam diante de seus alunos. Para o DOC3, o grande desafio das disciplinas de formação humana é fazer com que se consiga, "já na formação, enquanto aluno, ele perceba que ele continua e ele nunca deixou de fazer parte da sociedade que o aguarda enquanto profissional". Nesse ponto, foi perguntado a dois dos instrutores - DOC1 e DOC3 - se o regime de semi-internato não seria um paradoxo nessa formação humana e nesse desafio de criar um sentimento de pertencimento a uma sociedade maior. Neste ponto ocorreu um distanciamento de opiniões. Enquanto o DOC1 acredita que 
existe a real necessidade de um período de afastamento, digo afastamento para imersão numa doutrina, na vivência da caserna, para que se deixem hábitos e construam outros para que se possa trabalhar não só a condição intelectual, mas a condição de convivência, de relações interpessoais, de uma mudança de cultura daqueles que vêm do mundo civil e ingressam na vida militar.

\section{Para o DOC 3,}

eu defenderia períodos ao longo dos três anos, onde o aluno ele precisaria estar mais familiarizado e mais presente nessa realidade da academia... se o currículo propõe uma formação mais de sociabilidade, mais voltada pra uma proximidade com a comunidade como um todo, se torna então contraditório querer uma reclusão, e ao mesmo tempo em que essa pessoa depois de três anos chegue na sociedade com a visão de que ele agora precisa ser humano... eu defendo é que existam períodos necessários, mas com o objetivo bem definido; que a pessoa saiba por que ele vai passar três, quatro, cinco dias de uma semana naquele local.

Sobre esse assunto, Muniz (2001, p. 11) explica que as Polícias Militares e, consequentemente, seu "irmão mais novo", os Corpos de Bombeiros Militares, passam por uma crise de identidade iniciada com o fim da Ditadura Militar brasileira. A partir daí, percebe-se uma luta entre grupos diferentes que possuem percepções distintas sobre o ser policial militar. Para os defensores de uma instituição nos moldes antigos, o esforço por afastar "da doutrina militar aplicada à polícia ou do chamado 'Militarismo" conduziu as PM a uma outra armadilha doutrinária: o bacharelismo". Entenda-se bacharelismo por uma política institucional voltada exclusivamente à interpretação e utilização de normas como base do funcionamento da Corporação. No entanto, as atividades das polícias militares e, principalmente, dos Corpos de Bombeiros Militares, requerem muito mais do que um profissional que se limite a interpretar códigos, normas e manuais técnicos. Para ser um Bombeiro Militar o indivíduo precisa demonstrar um poder de adaptação a uma variada gama de possibilidades que vai enfrentar em suas atividades diárias.

Com relação às competências que os alunos deveriam adquirir e às estratégias pedagógicas utilizadas, os coordenadores que tiveram contato com a área operacional defenderam a necessidade do aluno, além de adquirir os conhecimentos técnicoscientíficos necessários à atuação profissional, desenvolver a capacidade de liderança, que é muito importante na profissão Bombeiro Militar, sobretudo para os futuros oficiais.

Por fim, os docentes/instrutores apontaram como principal desafio o rompimento das barreiras logísticas para o desenvolvimento do curso, assim como a necessidade de mudanças de atitudes do corpo docente e de revisões nos documentos de funcionamento do curso, como o Regulamento Interno( intensa permanência) e currículos de diversas disciplinas, adaptando-os para a realidade social e institucional 
existentes na atualidade. Outrossim, como modificações propostas, os DOC2 e DOC3 destacaram a necessidade de apresentar a realidade aos discentes com a "aproximação cada vez maior com outras instituições de ensino. Se a proposta é ter uma formação superior acadêmica, o aluno dessa instituição não pode se sentir diferente ou à parte da realidade que outros discentes de outras instituições de ensino superior vivenciam" (DOC3). Por outro lado, o DOC2 foi bem enfático ao afirmar a necessidade de aproximar o curso de formação de oficiais com as atividades diárias da corporação, no sentido de uma otimização do período do estágio profissional como forma de melhor preparar os estudantes para a atuação no dia a dia da profissão, aproximandoos tanto da realidade da Corporação quanto da sociedade que os espera enquanto profissionais.

\section{Considerações Finais}

Esta pesquisa se propôs a analisar o currículo para a formação do Bombeiro Militar elaborado segundo os princípios da Matriz Curricular Nacional. Para isso, estudamos a proposta curricular e realizamos entrevistas com os docentes/instrutores e coordenadores do curso. O modelo formativo tem como desafio definir um novo perfil e nova identidade para os agentes de Segurança Pública.

Neste contexto, as primeiras considerações apontam que os docentes e coordenadores possuem dificuldade em definir qual a real função deles dentro da formação, sobretudo quando trata da função de coordenador de curso. Atribuímos este fato à ausência de uma proposta de formação do CBMPE que estabeleça as diretrizes para a formação em cada nível de ensino - formação, especialização e aperfeiçoamento. Acredito que tal carência é resultado da falta de incentivo e vivência em atividades de pesquisa no CBMPE.

Destacamos o nível de escolaridade dos docentes do curso em pauta, onde percebese que todos os docentes entrevistados possuem outra formação acadêmica diversa da formação para o Corpo de Bombeiros e, além deste dado, metade dos docentes entrevistados possui Pós-graduação Stricto Sensu, ou seja, têm vivência com a área de pesquisa. Esse dado é relevante na realidade do curso e pode ser entendido como um aspecto positivo que poderia ser aproveitado para um estudo sobre as políticas formativas na corporação. A valorização desses profissionais é elemento crucial para iniciar qualquer reflexão e mudança na proposta de formação.

Diante do exposto, como sugeriu o DOC2, através de um estudo técnico acerca das atividades formativas no CBMPE é que se poderá evoluir no sentido de criar e efetivar uma política institucional.

Um segundo ponto de destaque no que tange à proposta de formação adotada 
atualmente diz respeito ao isolamento social dos cursistas tanto em relação à comunidade externa quanto com a própria Corporação. Entendemos que esse seja mais um ponto que precisa ser aprofundado e discutido sobre o tema da formação militar, uma vez que mesmo entre os docentes não há consenso, conforme exposto pelo DOC3, que afirmou que a manutenção do regime de internato ou de semiinternato ao lado de uma proposta curricular que vise a aproximação dos discentes com a sociedade representa um paradoxo.

Diante do exposto, entendo que a presente pesquisa contribui para a formação militar no Estado de Pernambuco, oferecendo um panorama geral acerca das atividades e formação em corporação.

Percebemos nas análises feitas nas entrevistas a necessidade de uma série de adaptações e recontextualizações à proposta da SENASP para a formação dos agentes de Segurança Pública que corresponda à prática vivida nas academias de formação militares.

\section{Referências}

ALMEIDA, Lucinalva Andrade Ataíde de \& SILVA, Geisa Natália da Rocha (2014). O currículo pensado do curso de Pedagogia: a pesquisa em questão. Revista e-Curriculum. 2(12), 1440-1456. Recuperado em: 15 julho, 2015, de: <http:// revistas.pucsp.br/index.php/curriculum/article/view/15552>

APPLE, Michael W. (2002). Repensando Ideologia e Currículo. In: MOREIRA, Antonio Flávio

Barbosa; SILVA, Tomaz Tadeu. Currículo, Cultura e Sociedade, (7. Ed). São Paulo: Cortez, p. 39-57.

BALL, Stephen (2001). Diretrizes políticas globais e relações políticas locais em educação.

Currículo sem Fronteiras, 1(2).

CRUZ, Lara Abreu (2013). Currículo e contra-currículo: uma análise da formação profissional dos soldados do ronda do quarteirão. Dissertação de Mestrado, Curso de Mestrado Acadêmico em Políticas Públicas e Sociedade, Universidade Estadual do Ceará, Fortaleza, Brasil. Recuperado em: 20 agosto, 2015, de http://www.uece. $\mathrm{br} /$ politicasuece/dmdocuments/lara_abreu_cruz.pdf.

GOFFMAN, Erving. (2015).Manicômios, prisões e conventos. Trad. Dante Moreira 
Leite. São Paulo: Perspectiva.

LOPES, Alice Ribeiro Casimiro (2005). Política de currículo: recontextualização e hibridismo.

Currículo sem fronteiras. 5(2), 50-64. Recuperado em: 15 de outubro, 2015, de <http://www.curriculosemfronteiras.org/vol5iss2articles/lopes.pdf>

(2008). Políticas de integração curricular. Rio de Janeiro: EDUERJ.

LUIZ, Ronilson de Souza. Ensino Policial Militar. 2008. Tese de Doutorado, Programa de Pós-Graduação em Educação-currículo, Pontifícia Universidade Católica de São Paulo, São Paulo, Brasil. Recuperado em: 18 de março, 2015, de http:// www.educadores.diaadia.pr.gov.br/arquivos/File/2010/artigos_teses/2011/ sociologia/teses/ronilson_souza_tese.pdf.

MACEDO, Elizabeth et al. (2011). Criar currículo no cotidiano. (3a ed.). São Paulo: Cortez.

MAINARDES, Jefferson (2006). Abordagem do ciclo de políticas: uma contribuição para a análise de políticas educacionais. Revista Educ. Soc. 27(94), 47-69. Recuperado em: 18 de março, 2015, de http://www.cedes.unicamp.br.

MAINARDES, Jefferson \& STREMEL, Silvana (2010). A teoria de Basil Bernstein e algumas de suas contribuições para as pesquisas sobre políticas educacionais e curriculares. Revista Teias. 11(22), 31-54. Recuperado em: 18 de março, 2015, de: <http://periodicos.proped.pro.br/index.php/revistateias/article/ viewFile/575/580>

Matriz Curricular Nacional para Formação em Segurança Pública. Brasília: Ministério da Justiça, 2003.

Matriz Curricular Nacional para Formação em Segurança Pública. Brasília: Ministério da Justiça, 2014.

MORIN, Edgar (2003). A cabeça bem-feita: repensar a reforma, reformar o pensamento. Trad. Eloá Jacobina. (8a ed.). Rio de Janeiro: Bertrand Brasil.

MORIN, Edgar, ALMEIDA, Maria da Conceição de \& CARVALHO, Edgar de Assis (Orgs.). (2013). Educação e Complexidade: os sete saberes e outros ensaios. Trad. Edgar de Assis Carvalho. (6a ed.). São Paulo: Cortez.

MUNIZ, J. (2001). A Crise de Identidade das Polícias Militares Brasileira: Dilemas e Paradoxos da Formação Educacional. Security and Defense Studies Review. 01, 177-198. 
PACHECO, José Augusto (2005). Escritos curriculares. São Paulo: Cortez.

WOODWARD, Kathryn (2014). Identidade e diferença: uma introdução teórica e conceitual.

In SILVA, Tomaz Tadeu (org.). Identidade e diferença: a perspectiva dos estudos culturais. (14a ed.). Petrópolis, RJ: Vozes, p. 7-72.

Getúlio Neves Sena Mestre em Educação, Culturas e Identidades pela UFRPE/ FUNDAJ. Possui especialização em Gerenciamento de Projetos pela Faculdade Guararapes (2014), graduação em Curso de Formação de Oficiais Bombeiro Militar pela ACADEMIA INTEGRADA DE DEFESA SOCIAL (2010) e em Licenciatura em História pela Universidade Federal de Pernambuco (2013). Atualmente é Capitão do Corpo de Bombeiros Militar de Pernambuco.

Ana de Fátima Pereira de Sousa Abranches Mestre em Educação pela Universidade Federal de Pernambuco (2000) e Doutorado em Educação pela Universidade Federal de Pernambuco (2009). Atua na docência do Ensino superior desde os anos de 2000. Atualmente é Analista em Ciência e Tecnologia (Pedagoga) da Fundação Joaquim Nabuco, e Coordenadora do Mestrado Acadêmico em Educação, Culturas e Identidades, em Associação com a Universidade Federal Rural de Pernambuco e Fundação Joaquim Nabuco. Pareceristas ad hoc da Revista Brasileira de Política e Administração da Educação (RBPAE), Consultora ad hoc da Revista Brasileira de Estudos Pedagógicos (Rbep). Desenvolve atividades de ensino, pesquisa e extensão na área de Educação, com ênfase em Política Educacional, atuando principalmente nos seguintes temas: Políticas Públicas em Educação- Projeto Político Pedagógico - Gestão da Educação Conselhos em Educação - Participação e Controle Social. 